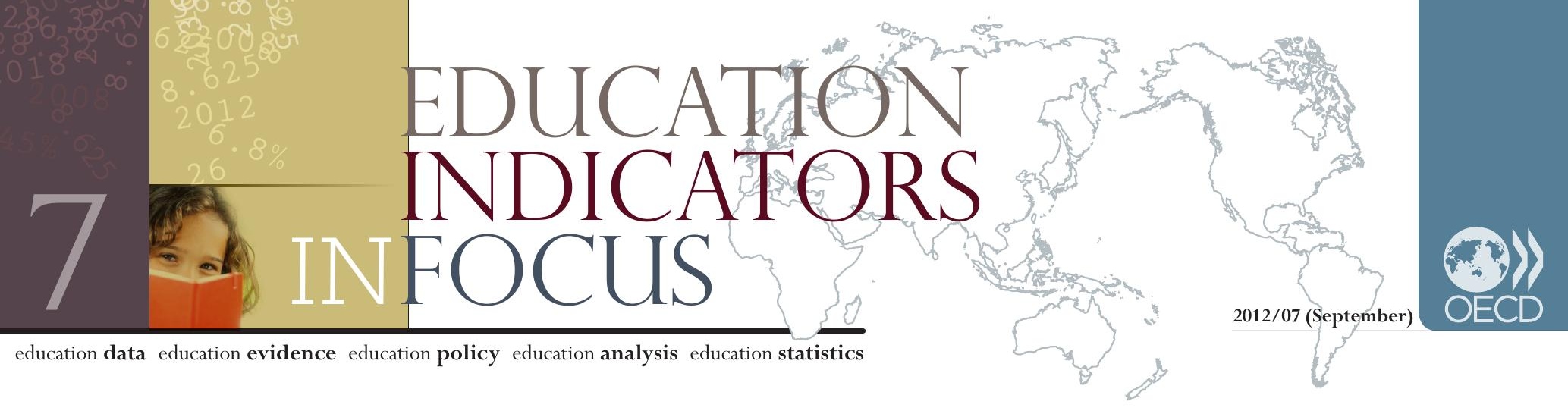

\title{
How well are countries educating young people to the level needed for a job and a living wage?
}

- An upper secondary qualification (ISCED 3) has become the norm for young people in OECD countries. Today it is considered the minimum qualification for successful participation in the labour market and for integration in society.

- In 2010, across OECD countries, $19.1 \%$ of 25-34 year-olds without an upper secondary qualification were unemployed, compared with $9.8 \%$ of young adults of the same age who had an upper secondary qualification.

- From 2004 to 2008, increasing upper secondary graduation rates coincided with declining numbers of 20-24 year-olds who were neither in education nor employed; but during the economic crisis, an upper secondary qualification no longer provided sufficient insurance against unemployment and poverty.

In many OECD countries, upper secondary attainment is becoming the minimum qualification level...

Rapidly changing economic and social conditions demand higher levels of skills. Although many students leave the education system before finishing upper secondary education, there is compelling evidence that, in OECD countries, students who leave school without an upper secondary qualification tend to face severe difficulties entering - and remaining in - the labour market. Some countries, like Portugal or the Flemish Community of Belgium, are increasing opportunities to acquire an upper secondary qualification at a later age through "second-chance" programmes. Others, like the Netherlands, have introduced measures in family-allowance legislation that complement compulsory education with the obligation to obtain a minimum level of qualification.

Over the past decades, almost all OECD countries have seen dramatic increases in educational attainment from one generation to the next. On average, $74 \%$ of $25-64$ year-olds had attained at least an upper secondary education in 2010, and $82 \%$ of 25-34 year-olds had. The average difference between the 25-34 and 55-64 year-old generations in OECD countries was 20 percentage points, but in Chile, Greece, Ireland, Italy, Korea, Portugal and Spain the difference was 30 percentage points or more.

Different measures are used to express how well a given population or age cohort is educated. The level of educational attainment is the percentage of a population that has reached a certain level of education, for example upper secondary education (ISCED 3). The graduation rate is the estimated percentage of a specific age cohort that is expected to graduate from a certain level of education at some point during their lifetime. The completion rate is the percentage of students who enter a programme for the first time and who graduate from it after a given number of years. 


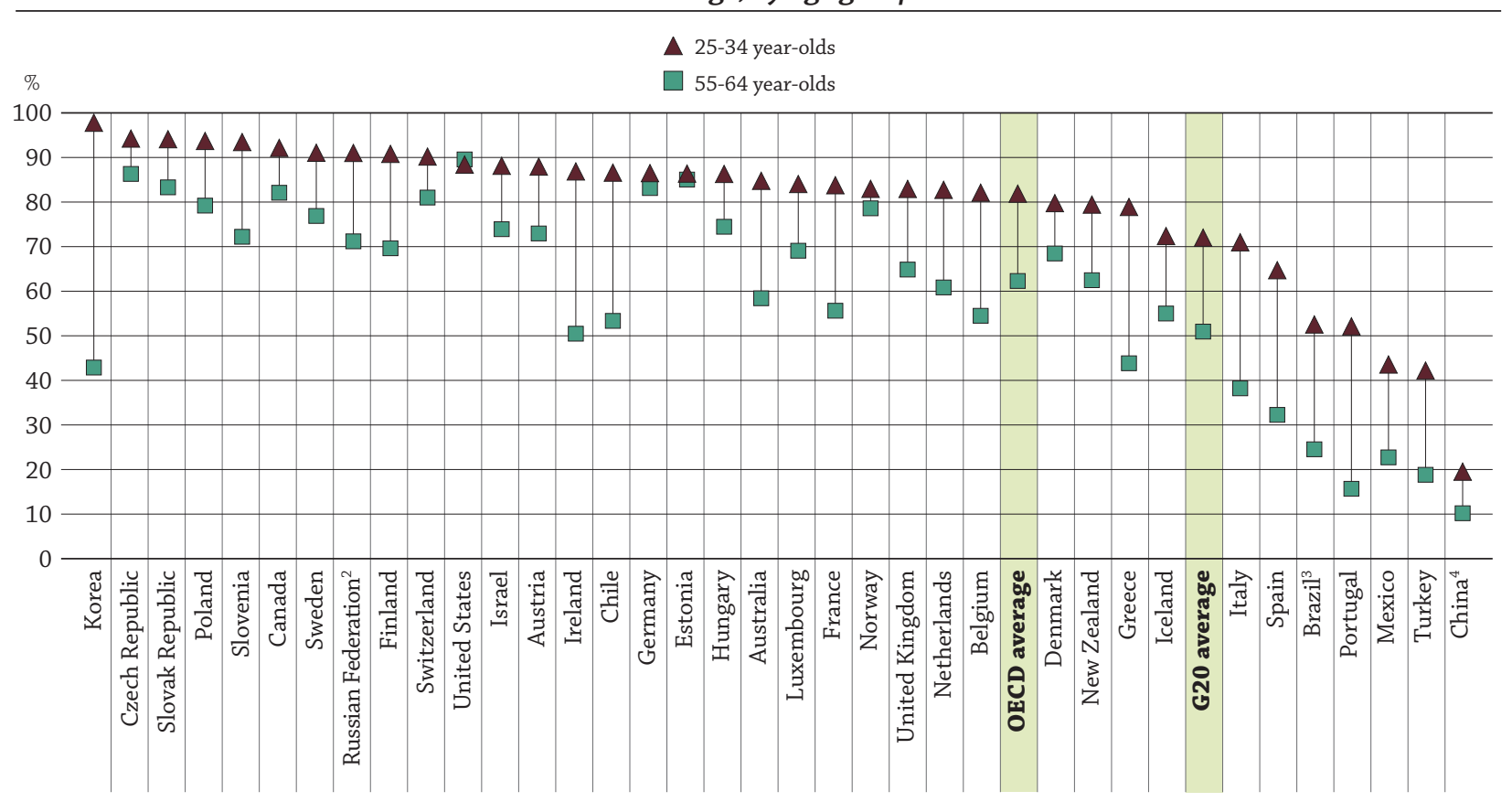

1. Excluding ISCED 3C short programmes.

2. Year of reference 2002.

3. Year of reference 2009.

4. Year of reference 2000.

Countries are ranked in descending order of the percentage of 25-34 year-olds who have attained at least an upper secondary education. Source: Education at a Glance 2012: OECD Indicators, Indicators A1 (www.oecd.org/edu/eag2012).

...but not all countries are successful in educating young people to that level.

A country's capacity to help young people to graduate from upper secondary education is the most important factor in improving attainment levels in successive generations. In most OECD countries, first-time upper secondary graduation rates now exceed $75 \%$, while countries like Finland, Greece, Ireland, Israel, Japan, Korea, Portugal, Slovenia and the United Kingdom have graduation rates equal to or above $90 \%$. These countries have successfully developed policies to increase the number of graduates from upper secondary school. In contrast, countries like the Czech Republic, Luxembourg, Mexico, Sweden, Turkey and the United States have graduation rates below $80 \%$.

\section{People without an upper secondary education are less employable and more likely} to get stuck in poverty traps...

Education and employment indicators consistently show that the more highly educated individuals are, the more likely it is that they will be employed. On average in 2010, the employment rate for 25-64 year-olds with an upper secondary qualification was $74 \%$, compared to $55 \%$ for individuals who have not completed this level of education. In addition, the probability of working full time in long-term employment increases with higher levels of education. Despite gender and age variations and considerable differences between countries, these data consistently show that an upper secondary education has become a prerequisite for improving employability. 
Low levels of education also increase the risk of poverty: some $27 \%$ of people without an upper secondary education earn less than half the median income - around 10 percentage points more than the proportion of people who do have that level of education. This difference in the relative risk of poverty is particularly striking (a gap of more than 15 percentage points) in Austria, Luxembourg, the Slovak Republic and the United Kingdom, and is widest (20 percentage points or more) in Korea and the United States. The difference is also far greater among women than among men: across OECD countries, the difference in the proportion of women who earn less than half the median income, based on whether or not they have an upper secondary education, averages 15 percentage points, while among men that difference is 7 percentage points. In 8 countries, the difference among women exceeds 20 percentage points.

... and less-educated youth are at particular risk.

Young men and women without an upper secondary education find it much more difficult to make the transition from school to work; and countries differ greatly in their capacity to integrate less-educated individuals into the workforce. Among the population that was neither employed nor in education and training (NEET) in 2010, there were 8 percentage points more 20-24 year-olds without an upper secondary education than 20-24 year-olds with that level of education. In 2010, in Estonia, France, Ireland, the Slovak Republic and Spain, at least 25\% of

the 20-24 year-olds who had not attained an upper secondary education were neither in school nor employed. By contrast, Denmark, Korea, Mexico and the Netherlands were able to limit that proportion of low-educated individuals who were unemployed to between $4.9 \%$ and $6.8 \%$.

\section{Evolution of total graduation rates and the share of the NEET population} among 20-24 year-olds (2004-2010)

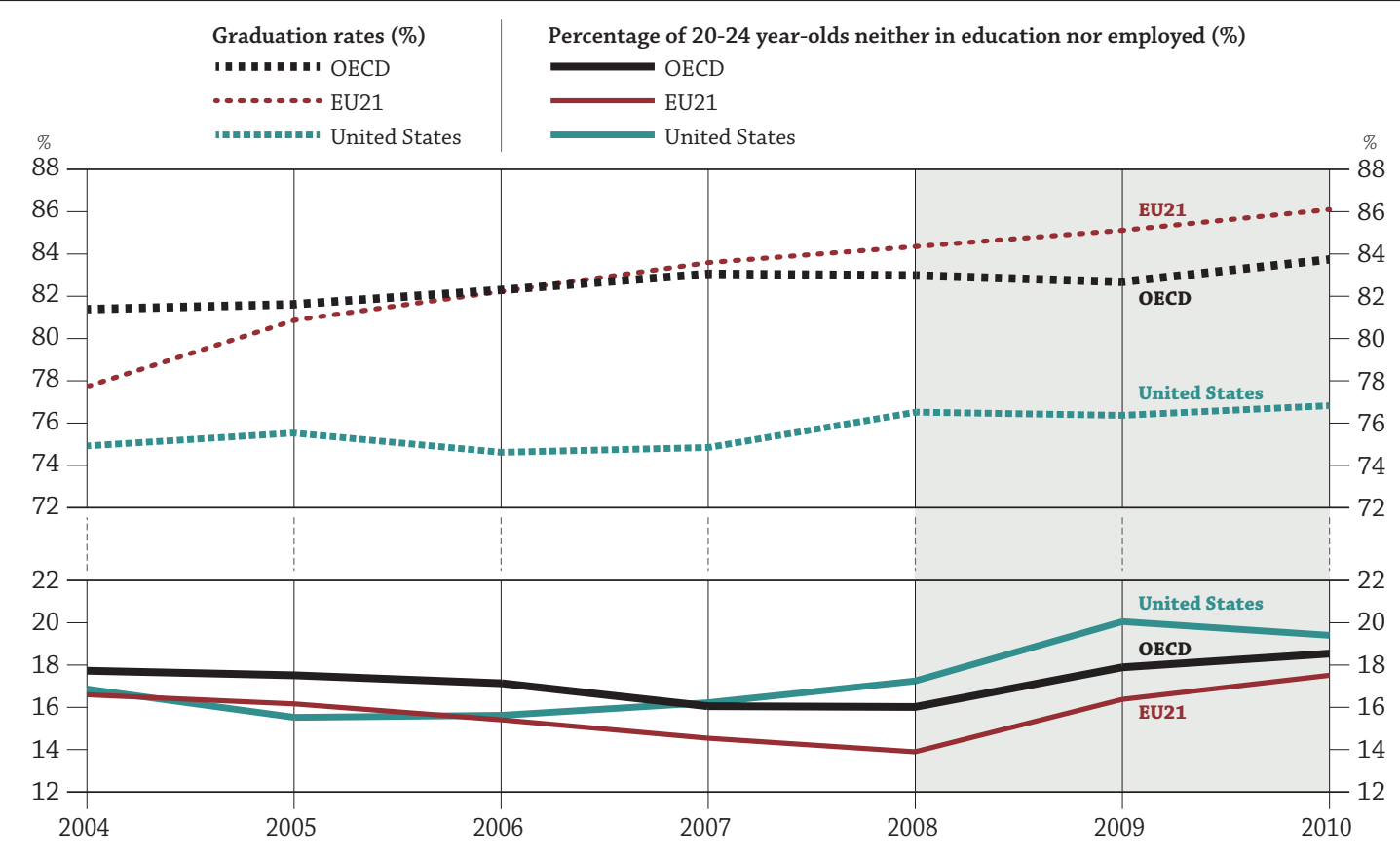

Source: Education at a Glance 2012: OECD Indicators, Indicators A2 and C5 (www.oecd.org/edu/eag2012). 
Higher levels of education help to mitigate these risks...

The evolution of upper secondary graduation rates over time seems to have had a positive effect on the size of the NEET population. Over the past ten years, average graduation rates have been increasing steadily in most OECD countries, especially in EU211 countries. The same is true for the United States, but at a lower level. At the same time, there has been a relative decline in the proportion of NEETs among 20-24 year-olds, at least until 2008. Policies in the EU21 countries have been particularly effective in reducing the share of unemployed among that age group between 2004 and 2008.

In the United States, the slight increase in graduation rates between 2004 and 2010 was not sufficient to significantly reduce the size of the NEET population. The situation also changed in EU21 and OECD countries in 2008, when the size of the NEET population started to swell. The economic crisis had clearly weakened the insurance against unemployment offered by upper secondary education. Indeed, those with slightly higher levels of education are now working in jobs that used to be filled by less-educated workers.

\section{...but during the recent economic crisis, the relative benefits of upper secondary attainment were pared down.}

Are the benefits associated with an upper secondary education sustainable over time - and during an economic downturn? Trend data on employment and earnings suggest that since the start of the crisis in 2008, the relative benefits of an upper secondary education have diminished somewhat. On average across OECD countries, the gap in unemployment rates between 25-34 year-olds without an upper secondary qualification and those with a tertiary qualification widened from 9 to 13 percentage points between 2008 and 2010, and in EU21 countries, it has widened from 11 to 16 percentage points (between those two years, this gap totaled more than 10 percentage points in Estonia, Ireland and the Slovak Republic).

Earnings tell a different story. Between 2008 and 2010 the earnings gap between people who have a tertiary qualification and those without an upper secondary qualification increased by 9 percentage points on average in OECD countries, but this increase was almost entirely due to the rise in earnings for highly qualified people. The evidence suggests that the crisis has accelerated job polarisation based on skills levels. People without an upper secondary qualification are highly vulnerable to unemployment, while those who have an upper secondary education are working for less money. This implies that a tertiary education is now a prerequisite for high-wage jobs.

1. The EU21 average is the unweighted mean of the data values for the 21 OECD countries that are members of the European Union for which data are available: Austria, Belgium, the Czech Republic, Denmark, Estonia, Finland, France, Germany, Greece, Hungary, Ireland, Italy, Luxembourg, the Netherlands, Poland, Portugal, Slovenia, the Slovak Republic, Spain, Sweden and the United Kingdom.

The bottom line People without an upper secondary education are at significant risk of unemployment and poverty. While most OECD countries have been able to expand educational opportunities so that more young people now have this minimum qualification, some have been less successful in doing so. And the economic crisis that began in 2008 is revealing that an upper secondary education is no longer solid insurance against unemployment and low wages.

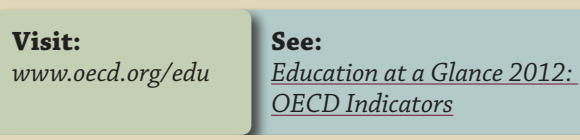

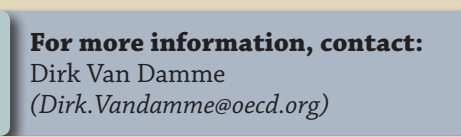

Coming next month:

Public and private investment in education 